\title{
Home Exercise DVD Promotes Exercise Accuracy by Caregivers of Children and Adolescents With Brachial Plexus Palsy
}

\author{
Lynnette Rasmussen, OTRL, Denise Justice, OTRL, Kate W-C. Chang, BS, MA, \\ Virginia S. Nelson, MD, MPH, Lynda J-S. Yang, MD, PhD
}

Objective: To evaluate the accuracy of home exercise performance by caregivers of children with neonatal brachial plexus palsy (NBPP) who use digital versatile disc (DVD) guidance.

Design: Prospective cohort study.

Setting: Brachial Plexus Clinic at the University of Michigan.

Participants: Seventy-six adult caregivers of a consecutive cohort of pediatric patients with NBPP.

Methods: Caregivers received the Home Exercise Program for Brachial Plexus Palsy DVD and an initial demonstration of correct hand placement and movement patterns by 1 of 2 occupational therapists. At times A, B, and C (approximately 3, 6, and 12 months), caregiver accuracy in exercise performance at each joint and standard measurements of arm function were recorded.

Main Outcome Measurements: Caregiver accuracy in correct hand placement and movement pattern during exercise performance was evaluated with use of a dichotomy scale (yes/no) at each joint. Active and passive range of motion were assessed as indicators of arm function.

Results: The mean patient age was 38 months, and the median Narakas score was 2. No significant difference in exercise accuracy for all upper extremity joints between the initial evaluation and times $\mathrm{A}, \mathrm{B}$, and $\mathrm{C}$ or between individual times was observed, except at the shoulder (98.9\% initially to $88.3 \%$ at time A; $P=.0002$ ) and elbow (100\% initially to $96.6 \%$ at time $A ; P=.04$ ). Regarding arm function, an increase in active range of motion for shoulder flexion, elbow flexion, forearm supination, wrist extension, and finger flexion was observed during the study period.

Conclusions: Shoulder and elbow exercises may be more complex, requiring more frequent performance review with the caregiver. However, the home exercise DVD may benefit patients with NBPP and their caregivers and may provide an adjunct to formal therapy sessions.

PM R 2013;5:924-930

\section{INTRODUCTION}

Neonatal brachial plexus palsy (NBPP) results in weakness and loss of sensation of the upper extremity that is associated with stretching of the nerves of the brachial plexus during the perinatal period. NBPP affects 0.4 to 2.6 per 1000 live births [1-4]. Although most affected infants recover spontaneously, 10\% to 30\% have residual impairment that requires further treatments [5,6]. Regardless of the severity and extent of the nerve injury, range of motion exercises augment other treatments in optimizing functional recovery.

Children with NBPP often receive supervised therapy sessions involving quality interventional strategies and monitoring of progress by professional therapists. Maintaining muscle balance and preventing joint contractures can prevent permanent secondary musculoskeletal abnormalities, including glenohumeral dislocation and osseous deformity [7]. Of note, both the timing and frequency of range of motion exercises are necessary to

L.R. Department of Neurosurgery, University of Michigan, Ann Arbor, Ml Disclosure: nothing to disclose

D.J. Department of Neurosurgery, University of Michigan, Ann Arbor, Ml Disclosure: nothing to disclose

K.W-C.C. Department of Neurosurgery, University of Michigan, Ann Arbor, Ml Disclosure: nothing to disclose

V.S.N. Department of Physical Medicine and Rehabilitation, University of Michigan, Ann Arbor, Ml

Disclosure: nothing to disclose

L.J-S.Y. Department of Neurosurgery, University of Michigan, Ann Arbor, Ml. Address correspondence to: L.J.-S.Y.; Department of Neurosurgery, University of Michigan, $1500 \mathrm{E}$ Medical Center Dr, Room 3552 TC, Ann Arbor, MI 48109-5338; e-mail: ljsyang@med.umich.edu Disclosures outside this publication: consultancy, FDA; grants/grants pending, University of Michigan internal grants (money to institution)

Submitted for publication February 5, 2013; revised June 3, 2013; accepted June 6, 2013. 
minimize muscle imbalance. Home exercise programs are crucial for achieving maximal functional outcomes in children with disabilities (eg, in the treatment of NBPP in a pilot study) [8]. Consequently, a home exercise program on a digital versatile disc (DVD) was created to target the NBPP population.

DVD use has resulted in increased compliance and frequency in performance of home exercise routines and is associated with preservation and/or improvement of function [9]. Additionally, accuracy in the performance of exercises affects the range of motion achieved or maintained. Occupational or physical therapists instruct patients and caregivers during formal clinical visits regarding the proper movements to perform. The efficacy of an exercise program relies upon caregiver motivation to perform exercises while maintaining the integrity of the movement [10]. Reo and Mercer [11] suggest that videotape modeling may be superior in encouraging correctness of the exercises being performed when compared with written handouts. However, the complexity of the exercise may preclude accurate performance. No studies exist that describe the effect of multimedia programs on exercise accuracy in patients with NBPP. Consequently, the purpose of our study was to evaluate the accuracy of caregiver performance of home exercises up to 1 year after receiving the home exercise program DVD.

\section{METHODS}

Approval for this study was granted by the University of Michigan Institutional Review Board.

\section{Participants}

Participants included 85 adult caregivers of children evaluated in the University of Michigan Brachial Plexus Program. Excluded from analysis were caregivers who were non-English speaking, caregivers of children who were filmed on the DVD, and caregivers of children undergoing surgical treatment during the survey period. As a result, a total of 76 caregiver evaluations were included for prospective analysis. All caregivers received the Home Exercise Therapy Program for Brachial Plexus Palsy DVD (which received the 2008 Fred P. Sage Multimedia Award at the American Academy for Cerebral Palsy and Developmental Medicine Annual Meeting in Atlanta, GA) at the initial evaluation, with a recommendation for exercise frequency. All caregivers had access to DVD players.

\section{Data Collection-Objective Evaluation}

At the patient's initial visit, 1 of our program's 2 occupational therapists (OTs)(D.J. and L.R.) demonstrated the exercise to the caregiver at the shoulder, elbow, forearm, wrist, and fingers and evaluated the caregiver's accuracy in the immediate repetition of the exercises with regard to correct hand placement and movement patterns [12]. The caregiver was then given the exercise DVD for continuation of home exercises. A dichotomy scale was applied for hand placement and movement accuracy at each joint (yes $=1$; no $=0$ ). For each joint, accuracy scores were added and divided by the movement numbers as an accuracy percentage. For example, if 5 of the 7 movements at the shoulder were completed, the accuracy percentage was $5 / 7=71 \%$. The same evaluation was completed at 3 predetermined times, represented by time A (predetermined at 3 months; actual mean, $5.4 \pm 3.6$ months), time B (predetermined at 6 months; actual mean, $9.9 \pm 4.2$ months), and time $C$ (predetermined at 12 months; actual mean, $15.3 \pm 5.9$ months). Accuracy percentages were compared among the times (A, B, and C). Attrition of participants (because of relocation, resolution of NBPP, missed appointments, and lost contact) resulted in 76 caregivers at the initial evaluation, 63 (83\%) at time A, 48 (63\%) at time B, and 28 (37\%) at time C. Demographics and median Narakas scores were noted at the initial evaluation.

\section{Range of Motion Measures}

Arm function was analyzed via a review of the measurements recorded by one of the OTs during clinic visits. Arm function indicators included active range of motion (AROM): shoulder flexion $\left(0-180^{\circ}\right)$, elbow flexion $\left(0-150^{\circ}\right)$, forearm supination $\left(0-90^{\circ}\right)$, wrist extension $\left(0-70^{\circ}\right)$, and finger flexion $\left(0-90^{\circ}\right)$ [12]. Functional measurements were obtained from an Institutional Review Board-approved dataset corresponding to the various times. Measurements of active shoulder flexion, elbow flexion, forearm supination, wrist extension, and finger flexion were compared for all times. All measurements were collected by one of the OTs.

\section{Statistical Analysis}

Demographics and descriptive statistics for DVD recipients are summarized in Table 1. A paired $t$-test was applied to compare differences between initial evaluation and follow-up times for median Narakas scores and mean child age. Exercise accuracy rates and corresponding AROM at each time are presented in Tables 2 and 3. To investigate whether a DVD is a useful resource for a home exercise program, we compared the accuracy rates between initial evaluation (in-person instruction) to time A using a paired $t$-test. Caregiver exercise accuracy rates after receiving the DVD (time A to times B and C) were also evaluated using a paired t-test.

Functional AROM comparisons between initial evaluation and follow-up time points were assessed using a paired $t$-test. All statistical analyses were performed using SAS software, version 9.2 (SAS Institute, Cary, NC). A $P$ value of $<.05$ was considered statistically significant. 
Table 1. Demographics of home exercise digital versatile disc recipients at initial and follow-up evaluations*

\begin{tabular}{|c|c|c|c|c|}
\hline & $\begin{array}{c}\text { Initial } \\
\text { Evaluation }\end{array}$ & Time A & Time B & Time C \\
\hline Total No. of caregivers evaluated & 76 & 63 & 48 & 28 \\
\hline \multicolumn{5}{|l|}{ Age range when receiving DVD } \\
\hline $0-12 \mathrm{mo}(\%)$ & $31(41)$ & $25(40)$ & $19(40)$ & $13(46)$ \\
\hline $1-6$ y (\%) & $31(41)$ & $28(44)$ & $22(46)$ & $8(29)$ \\
\hline Mean age of the child when the DVD was received (mo) & $38 \pm 45$ & $38 \pm 44$ & $34 \pm 45$ & $37 \pm 48$ \\
\hline $\begin{array}{l}\text { Mean difference in the child's age when the DVD was } \\
\text { received compared with the initial evaluation (mo) }\end{array}$ & & $0.4 \pm 7.6$ & $3.3 \pm 8.2$ & $0.3 \pm 10.1$ \\
\hline
\end{tabular}

DVD = digital versatile disc.

*No significant difference in mean age and Narakas score was found for each child at the initial and follow-up time points.

\section{RESULTS}

\section{Demographics}

Seventy-six caregivers were initially evaluated for exercise accuracy by one of the two OTs. After accuracy was evaluated, the exercise DVD was given to the caregiver. Study children had a mean age \pm standard deviation of $38 \pm 45$ months (range, 0-207 months) at the time the DVD was received, and a median Narakas score of 2. Caregivers were re-evaluated at various times as follows: 63 (83\%) completed at time A, $48(63 \%)$ at time B, and $28(37 \%)$ at time C. The mean age of the child upon receipt of the DVD and the Narakas score did not vary significantly among study participants (Table 1).

\section{Caregiver Exercise Accuracy}

Evaluations of shoulder exercise accuracy were available for $100 \%(\mathrm{n}=76)$ of caregivers at the time of the initial evaluation, $75 \%(\mathrm{n}=57)$ at time A, $57 \%(\mathrm{n}=43)$ at time $\mathrm{B}$, and $36 \%(n=27)$ at time C (Table 2). Shoulder exercise accuracy rate decreased from the time of initial evaluation (98.9\%) to time A $(88.3 \% ; P=.002)$. Changes from time A to time $\mathrm{B}(88.9 \% ; P=.69)$ and to time $\mathrm{C}(87.4 \%: P=.07)$ were not significant.
For elbow exercise evaluations, $100 \%(\mathrm{n}=76)$ of caregivers were available at the time of initial evaluation, $75 \%$ $(\mathrm{n}=57)$ at time A, 54\% $(\mathrm{n}=41)$ at time $\mathrm{B}$, and $32 \%$ $(n=24)$ at time C. Elbow exercise accuracy rate decreased significantly from initial evaluation (100\%) to time A (96.6\%; $P=.04$ ); however, no significant changes were seen from time A to time B $(99.4 \%$; $P=.15)$ or to time C $(95.8 \%$; $P=.86)$.

Forearm exercise accuracy rates were available for 100\% ( $\mathrm{n}=76$ ) of caregivers at the time of initial evaluation, $75 \%$ $(\mathrm{n}=57)$ at time $\mathrm{A}, 54 \%(\mathrm{n}=41)$ at time $\mathrm{B}$, and $33 \%$ $(\mathrm{n}=25)$ at time $\mathrm{C}$. The accuracy rate increased from time of initial evaluation (99\%) to time A $(100 \% ; P=.32)$; changes from time A to time $\mathrm{B}(97.5 \%$; $P=.32)$ or to time $\mathrm{C}(97.7 \%$; $P=.17)$ were not statistically significant.

Wrist exercise evaluations were available for 100\% $(\mathrm{n}=76)$ of caregivers at the time of initial evaluation, $75 \%$ $(\mathrm{n}=57)$ at time A, 54\% $(\mathrm{n}=41)$ at time $\mathrm{B}$, and $33 \%$ $(\mathrm{n}=25)$ at time $C$. Accuracy rates stayed the same from the time of initial evaluation to time A and time B (100\%), and the change from time A to time C $(95 \% ; P=.23)$ was not statistically significant.

For finger exercise evaluations, $100 \%(\mathrm{n}=76)$ of caregivers were available at the time of initial evaluation, $75 \%$ $(\mathrm{n}=57)$ at time A, 54\% $(\mathrm{n}=41)$ at time $\mathrm{B}$, and $30 \%$

Table 2. Percentage of exercise accuracy determined by an occupational therapist at the initial and follow-up evaluations*

\begin{tabular}{|c|c|c|c|c|c|c|c|}
\hline Joint & \multicolumn{4}{|c|}{ Correction Percentage } & \multicolumn{3}{|c|}{$P$ Values } \\
\hline Shoulder & $98.9(76)$ & $88.3(57)$ & $88.9(43)$ & $87.4(27)$ & .002 & .69 & .07 \\
\hline Forearm & $99(76)$ & $100(57)$ & $97.5(41)$ & $97.7(25)$ & .32 & .32 & .17 \\
\hline Wrist & $100(76)$ & $100(57)$ & $100(41)$ & $95.0(25)$ & - & - & .23 \\
\hline Fingers & $100(76)$ & $99.4(57)$ & $100(41)$ & $98.9(23)$ & .32 & .32 & .33 \\
\hline
\end{tabular}

*Shoulder exercise includes hand placement, shoulder flexion, external rotation abduction, external rotation adduction, internal rotation abduction, minimizing arching of the torso, and holding a stretch; elbow exercise includes hand placement, flexion, extension, and holding a stretch; forearm exercise includes hand placement, supination, pronation, and holding a stretch; and wrist and hand exercise involves hand placement, flexion, extension, and holding a stretch. Complete movement scores are added and divided by the movement numbers as an accuracy percentage; for example, if 5 of the 7 movements at the shoulder are completed, the accuracy percentage is $5 / 7=71 \%$. 
Table 3. Active range of motion (degrees) for study participants at initial and follow-up evaluations

\begin{tabular}{|c|c|c|c|c|c|c|c|}
\hline $\begin{array}{l}\text { Functional } \\
\text { Outcomes }\end{array}$ & \multicolumn{4}{|c|}{ Mean \pm Standard Deviation $(n)$} & \multicolumn{3}{|c|}{$P$ Values } \\
\hline Elbow flexion & $89 \pm 62(63)$ & $103 \pm 57(62)$ & $105 \pm 44(43)$ & $107 \pm 39(28)$ & .0003 & .0002 & .006 \\
\hline $\begin{array}{l}\text { Forearm } \\
\text { supination }\end{array}$ & $12 \pm 67(63)$ & $25 \pm 60(61)$ & $28 \pm 59(43)$ & $37 \pm 62(28)$ & .04 & $<.0001$ & .008 \\
\hline
\end{tabular}

$(\mathrm{n}=23)$ at time $\mathrm{C}$. The accuracy rate decreased from time of initial evaluation $(100 \%)$ to time A $(99.4 \% ; P=.32)$; changes from time A to time B $(100 \% ; P=.32)$ or to time $\mathrm{C}$ (98.9\%; $P=.33$ ) were not significant.

\section{Active Range of Motion}

AROM measurements from children whose caregivers participated in the study were available for $70 \%(n=53)$ of participants for shoulder flexion in adduction at the time of the initial evaluation, $74 \%(n=56)$ at time A, $53 \%(n=40)$ at time $\mathrm{B}$, and $36 \%(\mathrm{n}=27)$ at time C (Table 3). Active shoulder flexion increased significantly from initial evaluation $\left(86^{\circ} \pm 55^{\circ}\right)$ to time $\mathrm{A}\left(106^{\circ} \pm 56^{\circ} ; \mathrm{P}=.0002\right)$, time $\mathrm{B}$ $\left(108^{\circ} \pm 49^{\circ} ; P<.0001\right)$, and time $C\left(109^{\circ} \pm 50^{\circ}\right.$; $P=.005$ ), with an average total gain of $23^{\circ}$ from the time of the initial evaluation to time $C$.

Elbow flexion measurements were available for $83 \%$ ( $n=63$ ) of participants at the time of the initial evaluation, $82 \%(n=62)$ at time A, $57 \%(n=43)$ at time B, and $37 \%$ $(\mathrm{n}=28)$ at time $\mathrm{C}$. Active elbow flexion increased significantly from initial evaluation $\left(89^{\circ} \pm 62^{\circ}\right)$ to time A $\left(103^{\circ}\right.$ $\left.\pm 57^{\circ} ; P=.0003\right)$, time B $\left(105^{\circ} \pm 44^{\circ} ; P=.0002\right)$, and time $\mathrm{C}\left(107^{\circ} \pm 39^{\circ} ; \mathrm{P}=.006\right)$, with an average total gain of $18^{\circ}$ from the time of the initial evaluation to time $\mathrm{C}$.

Forearm supination measurements were available for $83 \%(\mathrm{n}=63)$ of participants at the time of the initial evaluation, $80 \%(n=61)$ at time $A, 57 \%(n=43)$ at time $B$, and $37 \%(n=28)$ at time $C$. Active forearm supination increased significantly from initial evaluation $\left(12^{\circ} \pm 67^{\circ}\right)$ to time A $\left(25^{\circ} \pm 60^{\circ} ; \mathrm{P}=.04\right)$, time B $\left(28^{\circ} \pm 59^{\circ} ; \mathrm{P}<.0001\right)$, and time $\mathrm{C}\left(37^{\circ} \pm 62^{\circ} ; P=.008\right)$, with an average total gain of $25^{\circ}$ from the time of the initial evaluation to time $\mathrm{C}$.

Wrist extension measurements were available for $83 \%$ ( $\mathrm{n}=63$ ) of participants at the time of the initial evaluation, $80 \%(n=61)$ at time A, $55 \%(n=42)$ at time B, and $37 \%$ $(\mathrm{n}=28)$ at time $\mathrm{C}$. Active wrist extension increased significantly from the time of the initial evaluation $\left(36^{\circ} \pm 42^{\circ}\right)$ to time A $\left(44^{\circ} \pm 43^{\circ} ; P=.07\right)$, time B $\left(46^{\circ} \pm 45^{\circ} ; P=.005\right)$, and time $\mathrm{C}\left(55^{\circ} \pm 35^{\circ} ; P=.017\right)$, with an average total gain of $19^{\circ}$ from initial evaluation to time $\mathrm{C}$.

Finger flexion measurements were available for 83\% ( $n=63)$ of participants at the time of the initial evaluation,
$82 \%(\mathrm{n}=62)$ at time A, $57 \%(\mathrm{n}=43)$ at time $\mathrm{B}$, and $37 \%$ $(\mathrm{n}=28)$ at time $\mathrm{C}$. Active finger flexion stayed the same from the time of the initial evaluation $\left(85^{\circ} \pm 18^{\circ}\right)$ to time A $\left(85^{\circ} \pm 18^{\circ} ; P=.52\right)$, decreased at time B $\left(78^{\circ} \pm 40^{\circ}\right.$; $P=.11)$, and increased at time $C\left(88^{\circ} \pm 10^{\circ} ; P=.82\right)$, with an average total gain of $3^{\circ}$ from the time of the initial evaluation to time C. Finger flexion showed no statistically significant change from initial evaluation through all followup appointments.

\section{DISCUSSION}

Traditionally, physicians and therapists educate caregivers on correct home exercise routine via in-person demonstration with verbal instruction and written handouts. Reproducing the exercise correctly from memory or written instructions outside of formal medical appointments is not as effective as face-to-face guidance [11]. Face-to-face instruction and dynamic modeling are more effective than written handouts [13-16], and the use of video instruction is more effective for achieving accuracy in the performance of basic exercise programs for the general population [11]. Therefore a DVD to aid in home exercise performance was developed to guide caregivers of patients with NBPP.

Routine practice combined with accurate exercise movements such as positioning, stabilizing, and stretching the joints can highly improve range of motion outcomes [12]. At the initial visit, the therapist demonstrates the exercise routine to the caregiver, including proper hand placement and movement patterns, before distributing the DVD; exercise accuracy at each joint is ensured immediately after demonstration (the initial time). Previous studies support our finding that in-person instruction is more effective than other methods with respect to exercise accuracy and compliance [13-15]. In this study, we investigated the effect of the NBPP DVD on home exercise accuracy. To our knowledge, this study is the first to investigate the accuracy of unsupervised home exercises performed by caregivers of children with NBPP. Despite the expected decrease in accuracy of unsupervised exercise movements over time, we found that accuracy did initially decrease significantly for shoulder and elbow exercises, but then stabilized during the study period. Therefore our results suggest that the use of 


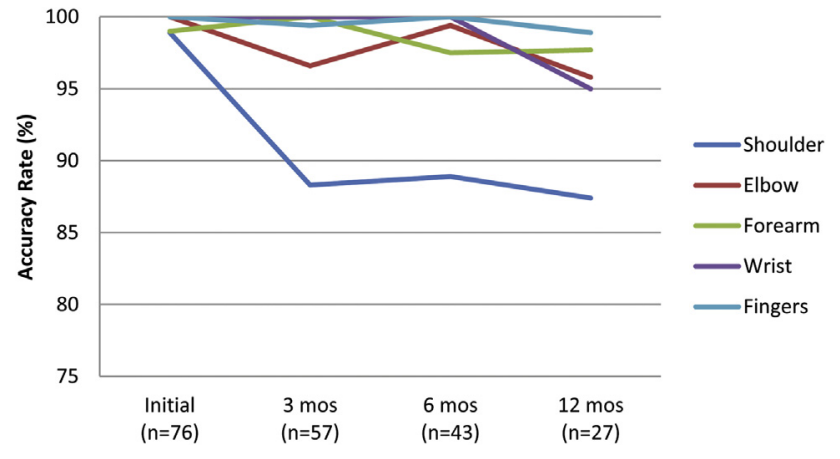

Figure 1. A line graph illustrating home exercise accuracy rates for affected anatomic areas at different examination times.

DVD instruction aids in maintaining accurate positioning during home exercise programs for persons with NBPP.

Accuracy rates for shoulder exercises declined significantly from the time of the initial evaluation to time A $(P=.002)$ (Figure 1$)$, suggesting that techniques to handle and protect the glenohumeral capsule might be difficult for untrained caregivers. Similarly, the accuracy rates for elbow exercises declined from the time of the initial evaluation to time A ( $P=.04$ versus the shoulder, which was $P=.002)$. The shoulder and elbow are more complicated joints, and positioning and stabilizing their large muscle groups requires more attention to maintain accurate movement patterns. We encourage physicians and therapists to review these portions with the caregiver on a regular basis to ensure the effectiveness of exercise.

AROM measurements were assessed concurrently at each time, and all the joints except finger flexion had significant improvement during the study period (Figure 2). The lack of significant change in finger flexion is most likely a reflection of almost normal active movement at the time of the initial assessment through time $\mathrm{C}$. We note that the improvement in AROM is an associated finding, and we do not suggest any causal relationship between DVD usage and functional improvements.

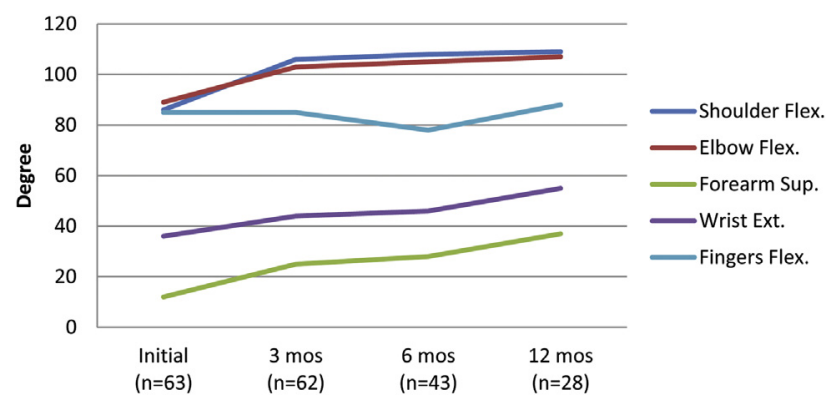

Figure 2. A line graph representing degrees of active range of motion for affected anatomic sites at different examination times. Flex = flexion; Sup =supination; Ext = extension.
As information technology advances, multimedia resources have affected health care services and practitioner interaction with patients. In our previous study [9], we demonstrated that DVD-assisted home exercises improved caregiver compliance and confidence, as well as the frequency and duration of exercise performed. Results also indicated that patients/caretakers preferred the use of the DVD compared with a written handout [9]. In this study, we demonstrated that DVD use aided in maintaining correct performance of the exercises. Improvement in arm function was concurrent with home exercise compliance in children with NBPP. Our experience is consistent with the findings for DVD use with other disorders such as osteoarthritis and hand injury and that DVD use in home exercise programs results in increased understanding of exercise requirements $[17,18]$. Other studies provide evidence that videos and CD-ROM media help improve patient compliance and education [19-22]. Compared with live instruction, alternative methods such as exercise DVDs are more cost-effective and time-efficient, and we predict that use of these multimediabased formats will become common to improve therapy compliance via home exercise programs.

From a clinical standpoint, the prevalence of shoulder muscle contracture and osseous deformity is found to be high in children with NBPP and is usually observed within the first 6 months after birth [23]. Once a shoulder contracture has occurred, secondary procedures may be needed to improve function. As the child grows, musculoskeletal deformity can lead to difficulty in performing daily activities [24]; in addition, the potential asymmetric physical appearance of a child with a glenohumeral deformity might further affect the child's self-image, along with other psychosocial aspects [23]. Likewise, the clinical importance of elbow flexion contracture in children with NBPP also may impair their ability to perform activities of daily living, including self-care, and needs to be monitored as well. Therefore every effort should be made to maintain full passive range of motion in all joints and to maximize active movements at an early stage [25].

Range of motion exercises prevent muscle contraction and maintain muscle balance for improving active muscle range $[8,26]$; however, without accurate performance and integrity of the movements, the effectiveness of the exercise program to provide functional recovery may be reduced $[15,27]$. We suggest that the use of a home exercise DVD aids in maintaining exercise accuracy and is a helpful supplement to home exercise programs for patients with NBPP.

\section{Study Limitations and Suggestions for Further Research}

Although a relatively large sample size may provide statistical significance, the limitations of the study remain challenging. First, all patients and their caregivers were recruited from a single institution. In addition, treatments and education 
regarding NBPP have been implemented since the birth of the patient; therefore, they might be more motivated or dedicated to perform home exercise accurately. Also, an innate bias is introduced in that recruited caregivers may be more aware because of their participation in the study and thus pay more attention to exercise details such as positioning, which might increase their exercise accuracy compared with caregivers who did not participate in the study. Overlap in the ranges for times A, B, and C because of variable subject availability may have inadvertently affected the results. Note that participant attrition was primarily derived from patients lost to follow-up, because none of the participants underwent surgical procedures during the study period. Finally, our OTs routinely review the home exercises after evaluating the caregiver's performance of the home exercises as part of standard care. This factor may detract from the effect of DVD. To minimize this effect, we compared accuracy rates from time of initial (in-person) evaluation to time A (after receiving DVD) to assess the DVD effect.

To establish more reliable clinical value for demonstrating the effect of DVDs on accuracy of exercise performance, future research should include comparison of a control group of patients who do not receive the DVD but are given the standard written home exercise program. Comparison of the AROM functional gain between the different age groups also could be instructive. Further studies evaluating the effectiveness of using video instruction for comprehension and participation, including more comprehensive comparison of improvement in function and to better evaluate home program outcomes, are warranted. Video instruction can be an economical choice, especially when therapy visits become limited, and thus evaluating the effectiveness of these supportive devices becomes important in the treatment of patients with NBPP.

\section{CONCLUSIONS}

The purpose of this study was to evaluate the accuracy of caregiver performance of home exercises up to 1 year after receiving a home exercise program DVD. Our results demonstrate that:

1. Although we expected unsupervised exercise accuracy to decrease over time, exercise accuracy with DVD use did not significantly decrease during the study period of 1 year, except at the shoulder and elbow. This finding may indicate that shoulder and elbow exercises are more complicated to position and stabilize and require a periodic review with the caregiver to maintain accuracy.

2. AROM improved progressively throughout the study period.

3. DVD instruction can be a useful reference to aid in maintaining accuracy of arm positioning during performance of home exercises for persons with NBPP.

\section{REFERENCES}

1. Foad SL, Mehlman CT, Ying J. The epidemiology of neonatal brachial plexus palsy in the United States. J Bone Joint Surg Am 2008;90:12581264.

2. Greenwald AG, Schute PC, Shiveley JL. Brachial plexus birth palsy: A 10-year report on the incidence and prognosis. J Pediatr Orthop 1984; 4:689-692.

3. Pondaag W, Malessy MJ, van Dijk JG, Thomeer RT. Natural history of obstetric brachial plexus palsy: A systematic review. Dev Med Child Neurol 2004;46:138-144.

4. Waters PM. Update on management of pediatric brachial plexus palsy. J Pediatr Orthop B 2005; 14:233-244.

5. Hoeksma AF, Wolf H, Oei SL. Obstetrical brachial plexus injuries: Incidence, natural course and shoulder contracture. Clin Rehabil 2000; 14:523-526.

6. Zafeiriou DI, Psychogiou K. Obstetrical brachial plexus palsy. Pediatr Neurol 2008;38:235-242.

7. Hogendoorn S, van Overvest KL, Watt I, Duijsens AH, Nelissen RG. Structural changes in muscle and glenohumeral joint deformity in neonatal brachial plexus palsy. J Bone Joint Surg Am 2010;92:935-942.

8. Novak I, Cusick A. Home programmes in paediatric occupational therapy for children with cerebral palsy: Where to start? Aust Occup Ther J 2006;53:251-264.

9. Murphy KM, Rasmussen L, Hervey-Jumper SL, Justice D, Nelson VS, Yang LJ. An assessment of the compliance and utility of a home exercise DVD for caregivers of children and adolescents with brachial plexus palsy: A pilot study. PM R 2012;4:190-197.

10. Miller JS, Litva A, Gabbay M. Motivating patients with shoulder and back pain to self-care: Can a videotape of exercise support physiotherapy? Physiotherapy 2009;95:29-35.

11. Reo JA, Mercer VS. Effects of live, videotaped, or written instruction on learning an upper-extremity exercise program. Phys Ther 2004;84:622633

12. Trombly Latham CA. Occupational Therapy for Physical Dysfunction. 3rd ed. Baltimore, MD: Williams \& Wilkins; 1989.

13. Friedrich $M$, Cermak $T$, Maderbacher $P$. The effect of brochure use versus therapist teaching on patients performing therapeutic exercise and on changes in impairment status. Phys Ther 1996;76: 1082-1088

14. Lin PC, Lin LC, Lin JJ. Comparing the effectiveness of different educational programs for patients with total knee arthroplasty. Orthop Nurs 1997;16:43-49.

15. Smith J, Lewis J, Prichard D. Physiotherapy exercise programmes: Are instructional exercise sheets effective? Physiother Theory Pract 2005; 21:93-102.

16. Weeks DL, Brubaker J, Byrt J, Davis M, Hamann L, Reagan J. Videotape instruction versus illustrations for influencing quality of performance, motivation, and confidence to perform simple and complex exercises in healthy subjects. Physiother Theory Pract 2002;18:65-73.

17. Kingston GA, Tanner B, Gray MA. A pilot study evaluating a home exercise DVD for patients who reside in a rural and remote location. J Rural Trop Public Health 2009;8:1-7.

18. Lysack C, Dama M, Neufeld S, Andreassi E. A compliance and satisfaction with home exercise: A comparison of computer-assisted video instruction and routine rehabilitation practice. J Allied Health 2005;34: 76-82.

19. Boamah LM, Bohren JR, Pentiuk S, Baker R, Yi M, Moyer MS. Development and testing of a CD-ROM program for improving adolescent knowledge of inflammatory bowel disease. J Pediatr Gastroenterol Nutr 2010;50:521-525.

20. Krouse HJ. Video modelling to educate patients. J Adv Nurs 2001;33: 748-757. 
21. Moore J, Fiddler H, Seymour J, et al. Effect of a home exercise video programme in patients with chronic obstructive pulmonary disease. J Rehabil Med 2009;41:195-200.

22. Vestergaard S, Kronborg C, Puggaard L. Home-based video exercise intervention for community-dwelling frail older women: A randomized controlled trial. Aging Clin Exp Res 2008;20:479-486.

23. Hoeksma AF, Ter Steeg AM, Dijkstra P, Nelissen RG, Beelen A, de Jong BA. Shoulder contracture and osseous deformity in obstetrical brachial plexus injuries. J Bone Joint Surg Am 2003;85-A:316-322.

24. Rosenbaum $P$, Stewart $D$. The World Health Organization International Classification of Functioning, Disability, and Health: A model to guide clinical thinking, practice and research in the field of cerebral palsy. Semin Pediatr Neurol 2004;11:5-10.

25. Price A, Tidwell M, Grossman JA. Improving shoulder and elbow function in children with Erb's palsy. Semin Pediatr Neurol 2000; 7:44-51.

26. Reid S, Hamer P, Alderson J, Lloyd D. Neuromuscular adaptations to eccentric strength training in children and adolescents with cerebral palsy. Dev Med Child Neurol 2010;52:358-363.

27. Rastall M, Brooks B, Klarneta M, Moylan N, McCloud W, Tracey S. An investigation into younger and older adults' memory for physiotherapy exercises. Physiotherapy 1999;85:122-128. 